\title{
Amorphization amid Fragmentation: Japanese Society 1990-2020
}

\author{
YOSHIO SUGIMOTO*
}

Beztvarost a fragmentace: Japonská společnost, 1990-2020

\begin{abstract}
This paper sketches the major sociological transformations of Japanese society of the last three decades, 1990-2020, which can be regarded as a crucial turning point in Japan's history. It first examines the marked paradigm changes that have occurred in Japanese studies. The paper then endeavours to unravel how such alterations reflect the structural changes caused by the penetration of neoliberalism, the decline of the manufacturing industry, and the expansion of cultural capitalism. After illustrating how these forces have fragmented social relations, the paper ends with a description of how Japanese society is becoming increasingly amorphous in its social structures and value orientations. The paper attempts to cast the shifts of these three decades into relief against the background of the previous three decades, 1960-1989, when Japan enjoyed spectacular economic growth.
\end{abstract}

Keywords: Japanese society; third opening; neoliberalism; cultural capitalism; amorphization; fragmentation

DOI: $10.14712 / 23363525.2021 .15$

\section{Shifting Paradigm of Japanese Studies}

A drastic shift occurred in the discourse on Japanese society around the turn of the twentieth century: what was previously imagined as a uniquely homogeneous group-oriented society is now understood as one rife with internal cultural diversity and class cleavage.

In the heyday of Japan's remarkable economic performance in the decades up to the 1980 s, the nation used to be portrayed as a distinctively uniform society with low levels of domestic variation and high degrees of internal consensus, embracing collectivist values as opposed to Western individualism. The Japanese were described as being exceptionally loyal to the groups and organisations to which they belonged. At the societal level, Japan was thought to be highly integrated, consensual, and conflict-free, with a remarkable degree of homogeneity and a distinctive tone of harmony. Placing these propositions at the core of analysis, the so-called Nihonjinron (theories on the Japanese) proliferated, with its refined form termed the group model of Japan as a society [Befu 2001].

In the three decades from the 1990s to the 2010s, however, the tables turned abruptly, with a growing list of academic publications depicting a Japanese society abound with internal cultural variations and class rivalries, an illustration almost antithetical to the previous version. In stark opposition to the Nihonjinron argument, Japanese society is now

* Prof. Yoshio Sugimoto, Emeritus Professor of Sociology, La Trobe University, Bundoora-Victoria, 3083 Australia. E-mail: y.sugimoto@latrobe.edu.au. This article derives partially from Sugimoto [2021]. 
labelled a divided society (kakusa shakai), a multi-class society in which class cleavages and social inequalities prevail [Chiavacci - Homerich 2017], with consolidated social stratification and a lack of intergenerational social mobility [Ishida - Slater 2011]. Challenging the notion that Japan is racially and culturally homogeneous, studies focusing upon multiple ethnic and quasi-ethnic groups mushroomed, pointing to the presence of many minorities around the country [Fukuoka 2000; Lie 2004; Weiner 2008]. Furthermore, research on gender diversity intensified across disciplines, and Japan's popular culture attracted global attention [Iwabuchi - Tsai - Berry 2020]. Thus, Japan is increasingly portrayed as a multicultural society [Denoon - Hudson - McCormack - Morris-Suzuki 1996] comprising a mosaic of numerous subcultures and countercultures.

The volte-face in Japanese studies' research paradigm is attributable to the dramatic visibility of fundamental divisions in a few particular areas. From political economy and sociology of knowledge perspectives, four structural conversions are of paramount significance: the advance of globalism, the rise of cultural capitalism, the fragmentation of social relations, and the amorphization of structures and values.

\section{The Spread of Neoliberal Globalism}

In international comparison, the relative decline of Japan's economic position is undeniable. In 2010, China overtook Japan as the second-ranking superpower in terms of total gross domestic product. According to 2018 OECD data [OECD 2019], South Korea has almost caught up with Japan in terms of per capita GDP and labour productivity (GDP per person employed). It is obvious that Japan's economy has failed to deal with the advance of neoliberal globalisation around the world.

The three decades to 2020 were the third turning point in Japan's modern history to be propelled by external pressures (gaiatsu) [Mouer 2017]. The Meiji Restoration marked the first radical transformation that took place in reaction to the advancement of Western powers in Northeast Asia. In the second turn, the allied occupation after World War II, programs modelled on the United States proliferated across Japan. The third turn resembles the first two in terms of the strength of outside influences, although this time, it was the forces of neoliberal globalisation that landed in the country. Arguably, a "great transformation of Japanese capitalism" [Lechevalier 2014] and "Japan's quiet transformation" [Kingston 2004] took place at this point.

This third shift came at both state and business levels. Regarding the state, the "Japanese-style" development model had to be revised. It was once the case that the national bureaucratic ministries led the private sector by planning long-term programs and regulating it to defend what they regarded as national interests [Johnson 1982]. Proving to be inefficient and ineffective against the forces of globalisation, this developmental state model was undermined and partially abandoned, with the privatisation of key government corporations, which used to oversee the postal system, railway networks, highway routes, telegraph and telephone infrastructure, and so forth. A "regime shift" [Pempel 1998] was underway.

Most importantly, Japan's major banking institutions used to operate under the tight state controls on the financial sector. The practice referred to as the "convoy system" involved the national bureaucracy allowing all financial institutions to keep pace with weak 
ones and instructing them to avoid inordinate competition. This maintained the stability of the sector, thereby increasing its profitability in general. Japan's "financial big bang", the large-scale reforms implemented in 1996-2001, attempted to abolish this system and to introduce a range of liberalisation programmes predicated upon the free-market principles of internationally prevailing neoliberalism [Vogel 2006].

In the corporate sphere, Japanese-style work practices were forced to give way to more performance-based arrangements in order to compete with the low costs of production abroad. The celebrated lifetime employment scheme, for example, turned out to be obsolete, with nearly half of Japan's labour force now non-regular workers - part-timers, casuals and temporaries - with little guarantee of job stability. In 2019, 38.3 percent of the nation's workers fell into this category [MIC 2019]. At the same time, seniority-based wage structures were increasingly replaced with output-oriented models. Though the "Japanese-style" management patterns used to prevail only among male regular workers mainly in large corporations in the manufacturing sector, they provided the normative framework for the entire labour force, and their weakening had profound effects on the rest of the working populace.

The spectacular success of Japan's economic performance in the 1970s and 1980s planted the seeds of the problem. The wage gap between the Japanese workforce and its counterparts in other Asian countries widened to the extent that it became rational for Japanese companies to produce their goods offshore. In pursuit of cheap labor, they established firms in Asia and shifted their production base to China and beyond. This was external pressure of another kind, though the process was founded not on political enforcement but on economic rationalism. The made-in-Japan brand was replaced by the designedin-Japan and made-in-China trademark. Most notably, the domestic production base of Japanese automobiles and electrical appliances which once swept the world was eroded and gradually hollowed, with the number of workers in the manufacturing sector dwindling since the 1990s. Furthermore, the rapid development of information technology and assembly-line and office automation took over considerable parts of work performed by blue-collar workers and clerical employees and made them redundant, another process that contributed to the constriction of the manufacturing industry.

In contrast, the tertiary sector which consists of the production of services and other intangible goods has consistently expanded, with three quarters of the Japanese work force employed in this sector by the turn of the twentieth century. Considering that half the working population (46.9 percent) were engaged in agriculture in 1955 [Hashimoto 2018: 228 ], the shift to the production of chiefly non-physical commodities is significant.

\section{Rise of Cultural Capitalism}

Born of the large tertiary service sector, the fourth sector grew rapidly, showing its competitive edge internationally. This is the quaternary sector that specialises in the production of knowledge, information, symbols, taste, preferences, comfort, finesse, and other intangible value-adding goods, which can be broadly called cultural goods.

The cultural industry is predicated on four pillars which overlap to some extent: the knowledge industry (including IT software programming, teaching and research, journalism, book publication); the entertainment industry (comprising TV programmes, movies, 
manga, animation, music, performing arts, and fashion); the hospitality industry (made up of hotels, restaurants, tourism, sightseeing, and cuisine); and the health industry (composed of welfare, medicine, pharmacy, aged care, funerals, nursing, and fitness facilities). Most of these industries require labour-intensive work dependent upon human flexibility and adaptability.

The spread of the quaternary sector altered the demography of labour. Calculated from the Economic Census [MIC 2016], by 2016 the proportion of workers in this sector (38.7 percent), whom we might call cultural workers, far exceeded that of manufacturing workers (15.6 percent) [Sugimoto 2021: 126]. Evidently, Japan has been moving in the direction of cultural capitalism as distinguished from industrial capitalism. Stretching the reach of this domain both domestically and internationally, Japan's economy has found a way out of the post-industrial impasse.

Most noticeably, Japanese popular cultural goods produced in the quaternary sector gained an international fan base. Japanese manga, anime, sushi, Japanese cuisine, sudoku, J-pop, Hello Kitty, and Japanese fashion designs are global phenomena, attracting urban youth and others around the world. To characterise such trends, Douglas McGray [2002] coined the concept, Gross National Cool, arguing that while Japan is no longer a world superpower in terms of gross national product, it leads other nations in terms of GNC, a notion that captured an aspect of the emerging configuration. The idea propelled the Japanese establishment to organise the "Cool Japan" project in fresh pursuit of Japan's position as a soft power.

As Japan's popular culture attracted global attention, the serious, hardworking, perseverant representations of company employees were replaced with the funny, entertaining, and vivacious characters of manga and animation. Though the complete reverse of the old images, the new styles have been able to spread around the world with ease, benefitting from the long-standing, global reputation of Japanese industrial goods as high quality products. The international credibility of Japanese cars and electrical goods has leant legitimacy and desirability to its cultural products.

Though ostensibly glamourous and ahead of the times, the "Cool Japan" scheme has been compatible with the imperatives of the old-fashioned exploitation structure. For instance, the labour conditions of anime production are unstable, precarious, and harsh in contrast to the colourful and stylish images the industry promotes. A case in point is the animators who produce the hand-drawn frames that move the characters on screen. Though performing the most important work in the production process, most animators are freelance workers on low wages in an insecure work environment, hired by small companies on the bottom of the subcontracting ladder. At the top of the hierarchy of each anime production is the project committee comprising a publishing house, a TV station, and other media organisations. They usually outsource the material task to a subcontractor, who often subcontracts it on to a lower-tier firm. Thus, animators work at the lowest layer of the old-fashioned, multi-level, stratified structure.

In the quaternary sector more broadly, the casualisation of labour has been the most discernible shift, a trend in part attributable to the ample supply of women prepared to work on a casual basis without job security. Many of them were freed to a certain extent from labour-intensive household chores like cooking, washing, and cleaning due to widely available electrical goods. At the same time, business owners and managers were in search of 
low-cost labour, a requirement that women were able to satisfy. It goes without saying that the rise of feminist consciousness was also a significant contributing factor. By the middle of the 1990s, the number of "full-time housewives" who stayed home and did not engage in gainful work outside consistently declined and was overtaken by the number of two-income households where both husband and wife were in paid employment [JILPT 2019].

As a result, the quaternary sector is sharply stratified into two groups. At the top tier, a small number of professionals with highly specialised skills earn handsome salaries and enjoy luxurious lifestyles, while a large number of casualised workers on low wages operate below them. This dualised structure epitomises the broad class structure of Japanese society at large.

\section{Fragmentation of Social Relations}

The casualisation of labour has made appreciable dents to civil organisations. Hired and fired easily, these temporary employees are internally heterogeneous, unorganised, and disconnected from each other. With very limited personal ties in workplaces, people have tended to be disinterested in actively engaging with others in community life in general. Specifically, voluntary associations, which sit between individuals and the state, have lost members in significant numbers. Those citizens with no affiliation to them constituted nearly half of the eligible voters in 2019 (44.4 percent), almost 2.5 times as many as three decades ago (18.3 percent in 1990), as Table 1 exhibits.

Table 1: Affiliation to voluntary associations (Percentage of voters)

\begin{tabular}{|c|c|c|c|}
\hline & 1990 & 2019 & Change \\
\hline None & 18.3 & 44.4 & $\Delta \mathrm{Up}$ \\
\hline Neighbourhood & 67.6 & 23.9 & $\nabla$ Down \\
\hline Hobby & 17.1 & 13.6 & $\nabla$ Down \\
\hline PTA & 14.3 & 7.2 & $\nabla$ Down \\
\hline Labour unions & 8.2 & 6.1 & $\nabla$ Down \\
\hline Religious & 3.6 & 2.9 & $\nabla$ Down \\
\hline Agricultural \& fishery & 19.6 & 3.0 & $\nabla$ Down \\
\hline Commercial and industrial & 6.9 & 1.6 & $\nabla$ Down \\
\hline Senior citizens' groups ${ }^{*}$ & & 5.1 & \\
\hline NPO and community building associations ${ }^{*}$ & & 1.7 & \\
\hline Resident, consumer, or other civil groups ${ }^{*}$ & & 0.6 & \\
\hline
\end{tabular}

Adapted from [Akarui Senkyo Suishin Kyōkai 2020; Mori - Kubo 2014: 203; Nakakita 2017: 196]

Note: The groups marked with asterisks have only been included since 1993 and, therefore, 1990 figures are unavailable.

Notably, the neighbourhood associations - community-level voluntary organisations [Pekkanen - Tsujinaka 2014] which provide channels of communications and directions from local governments to households - that used to be the backbone of administrative 
control from above, have lost their membership over time. Once virtually all Japanese households were organised into these networks across the country, with semi-mandatory membership imposed on each household. The structure had rapidly corroded and shrunk by the turn of the last century, with less than a quarter of the Japanese now participating in it. The membership of labor unions - the collective basis to unite workers - also experienced a rapid decline to half of its previous total. Agricultural cooperatives, industrial and commercial groups, and parent-teacher associations have all shown similar trends. So have religious groups and hobby groups. The "de-organisational slide" is underway on a massive scale, with the fragmentation of social relations in progress.

Transformative and reformist civil associations - such as volunteer groups and non-profit or non-governmental organisations - have emerged afresh in recent decades, showing more global and informational orientations. However, their numbers are still small and limited, following the overall pattern of de-organisation.

Individualisation is in motion in other areas, too. In terms of voting behaviour, more than half of the national electorate are the swing voters who do not have structured loyalty to political parties. In local elections for prefectural and municipal representatives, the voter turnout has declined to approximately 50 percent, with half of the electorate showing no interest in participating. In one extreme case, only 25 percent of eligible voters cast a ballot in the prefectural governorship election in Saitama prefecture in 2011.

Public survey data collection for statistical purposes has also become difficult. In the twentieth century, virtually all citizens filled out forms for the National Census conducted every five years. In the 2015 Census, however, some 13.1 percent of the population failed to submit their data. The figure in Tokyo amounted to 30.7 percent [Kyoto 2020], an indication that privacy concerns and general apathy towards institutions are on the rise in metropolitan areas in particular.

What we do know from census data is that the nation's family structure has undergone a dramatic transformation. The 2015 Census shows that single-person households comprise the largest share, accounting for approximately one third of the total, with nuclear families consisting of married couples with a few children forming only a quarter [SBJ 2017]. The idealised image of the Japanese family, a husband and wife raising their sons and daughters, does not depict the representative reality. Moreover, the divorce rate has been on the increase. For every three marriages that take place, one divorce comes through, a sign that gender relations have become uncertain. Even after marriage, many women are reluctant to have children, reducing the birth rate and lowering the population growth. Further, many either cannot or do not choose marriage as an option. According to the 2015 Census, 23 percent of men and 14 percent of women never get married throughout their lifetime. In 1985, the proportion was less than 5 percent for both.

The above snapshots simply constitute the visible tip of the iceberg. Simultaneous with the development of this fragmentation has been the increasing privatization of individuals in many parts of Japanese society. From voluntary organisations through political behaviour to family life, a rising number of Japanese are in pursuit of private interests rather than collective gains. Privacy and anonymity are extensively cherished as important social values.

At the psychological level, such transformation manifests itself in acute form in the growth in number of people called hikikomori (social recluse), youngsters who stay in 
their room without leaving their house for many years, spending most of their time playing computer games, watching television, or just doing nothing [Zielenziger 2007]. With their numbers estimated to exceed one percent of the population, the trend represents the sharpest end of the disintegration of collective ties in Japanese society.

It is almost a cliché to suggest that the expansion of the internet has fundamentally changed the world. Virtual connectivity has made it possible for users to engage in instantaneous communications without tangible encounters. The users of social networking services (SNS) in particular have been able to interact with individuals without faceto-face meetings. In this environment, it is not imperative for them to have friends and acquaintances in the conventional sense, a condition which enables them to live in physical isolation while still maintaining virtual social connections.

The outbreak of COVID-19 in 2020 extended internet-dependent lifestyles further, facilitating "telework", "teleconferences", and many other forms of work able to be performed at home. The spread of the pandemic revealed that many jobs, particularly in the knowledge and information industry in the quaternary sector, can be conducted outside conventional workplaces, transcending geographical locations and boundaries. Squarely at odds with the Nihonjinron thesis of "Japanese groupism", the new work practice has encouraged social distancing in more than one way.

During the three decades since the 1990s, social relations and close communities have dwindled significantly as a result of the infiltration of neoliberalism, the attenuation of the developmental state, the casualisation of labour, the rise of cultural capitalism and the information revolution. The confluence of these forces has disintegrated and disjointed Japanese society and made it more diverse, heterogenous, and even amorphous in its configuration.

\section{Amorphization of Society}

While Japan is losing in global comparisons in many other respects, it proves "number one" internationally as an ageing society, with its rapidly rising life expectancy and declining birth rate. The rate of increase in longevity has been unprecedented in the world and caught most of the nation's policy makers by surprise.

This has resulted in a shrinkage of the young labour force that supported the growth of the Japanese economy, while the proportion of post-retirement senior citizens has burgeoned. The ratio of those at and above the age of sixty-five in the total population was 28.4 percent in 2019 [SBJ 2019], the highest in the world, far ahead of Italy (23.0 percent) and Portugal (22.4 percent), respectively ranking second and third. Illustrating the dramatic rise, the Japanese figure jumped from just 12.1 percent in 1990. At the end of the 2010s, two persons between the ages of fifteen and sixty-four are supporting one senior citizen, and the situation is likely to worsen. To meet the relative labour shortage of the younger generations, the Japanese business world was forced to open up and expand the employment market to three demographic groups, a solution which has inevitably made Japan's workforce much more diverse than before.

First, Japan's job market requires women as a boundless and relatively flexible supply of labour. Their job participation rate has steadily increased, flattening the so-called M-curve. The female workforce is more diversified than its male counterpart. A majority of women 
are employed as non-regular workers, variously classified into part-timers, casuals, temporaries and so on. Female regular employees are divided into two groups: career-track women who are required to perform the same duties as their male counterparts, and "ordinary" female employees who do clerical work and other less demanding jobs. As a result, the income differentials of women are much larger than those of men, and their values and lifestyles are much more manifold than males' [Tachibanaki 2010].

Second, the country needs to inject foreign workers into the system. Initially, the intake was limited to the descendants of Japanese overseas, mainly in Brazil. This endeavour was in accordance with the nation's controversial ideology that assumed the reliability of Japanese offspring. Facing a serious worker shortfall, however, the Japanese employment market had to broaden its overseas intake to recruit both highly skilled professionals and unskilled labourers working in the margin of the Japanese economy, most of whom are from Vietnam, Thailand, the Philippines, and Indonesia as well as China and South Korea. The number of foreign workers in Japan amounted to 1.66 million in 2018 [MHLW 2019], further diversifying the nation's labour force.

The third group to be recruited has been senior citizens themselves. Most of them work as part-timers and casuals, constituting 13.8 percent of the entire workforce in 2018 [SBJ 2019]. This is an unprecedented proportion, likely to increase rapidly in future. The retirement age was conventionally fifty-five until the early 1990s when companies were encouraged to move it to sixty. In 2013, this shift was formalised when the revised Elderly Employment Stabilization Law mandated that the retirement age be at least sixty-five. The legal framework is lagging behind the reality, with the average life span at 87.5 years for women and 81.4 years for men in 2019 [MHLW 2020], with the number of centenarians exceeding eighty thousand in 2020. The greying of the workforce has allowed older generations to participate in and influence work culture, changing its shape and widening its scope.

As Japan's workplaces turn demographically heterogeneous, it is inescapable that their work culture is becoming diversified, leaving behind the monocultural landscape of workplaces solely made up of male, Japanese, young and middle-aged workers. These structural transfigurations have given rise to changes in the social awareness, group classification, and self-identity of the populace. Specifically, social categories - such as consumers, workers, citizens, and nationals - with which people used to identify have lost stability. Far from "pure" and "crystalline" entities, it became obvious that these groups are not composed of monolithic individuals sharing the same attributes but are made up of a mixture of different sorts.

Consumers, for instance, are now less interested in purchasing goods standardised for mass consumption than in making personalised choices from among diversified products. Producers must target individualised and differentiated groups whose preferences are divided and selective. Consumer markets are neither uniform nor undifferentiated, with customers forming "segmented masses" [Hakuhōdō Institute of Life and Living 1985] that seek goods in tune with their personal tastes and preferences. Moreover, consumer choices are complicated because the subsistence needs of the Japanese have generally been satisfied. Most have a television set, rice cooker, phone, computer, washing machine, and other essential goods for the comfort of their daily life. In the contemporary post-subsistence phase, they prioritise different dimensions - such as asset accumulation, occupational 
prestige, and quality of life - and attempt to acquire "upper goods" [Hara - Seiyama 2005: 164-167] like high-end housing, luxury holidays, living abroad, getting postgraduate education, adopting ecological lifestyles, and pursuing other cultural commodities.

While juxtaposed solidly against capitalists and employers during the Cold War era, workers in post-growth Japan ceased to be deemed a homogeneous category. Labour unions used to define themselves as representatives of workers and their families and call for worker solidarity and camaraderie, but with the increase of non-regular workers, this form of collectivisation no longer fits the reality. It is evident that regular workers' advantaged positions derive from the low wages and job insecurity of non-regular workers. Indisputably, the interests of these two types of workers are in conflict. Organised labour, which is based in enterprise unions in the large-corporation sector, cannot claim to stand for the benefits of all workers. Many non-regular workers are female part-timers and casuals, circumstances that make it difficult and complex to identify who "we workers" are, and bringing gender into play in attempts to define them.

The same applies to the notion of citizens. For long, it represented the images of liberal, reformist, and well-informed individuals who were expected to form the engine of civil society in Japan. Urbane and transformative, they distinguished themselves from workers and class-based groupings. Citizens' movements started in the 1960s, identifying themselves as "ordinary people" in pursuit of progressive changes. In post-growth Japan, however, reactionary groups have emerged [Higuchi 2016], also labelling themselves as citizens. Some demanded the revision of history textbooks to justify the Japanese military's wartime activities, while others developed hate-speech campaigns to verbally attack minority groups, particularly resident Koreans. The category of citizens, thus, embraces competing components, making the term multi-shaded and indeterminate.

The concept of the Japanese national (Nihonjin), like that of citizens, does not turn out to be self-evident [Fukuoka 2000; Amino 2012; Oguma 2014]. The representation of racially and culturally uniform Japanese is increasingly problematic, and their diversity has come to light due to a complex set of factors. More than two million overseas migrants live in Japan, and as noted above, their presence is indispensable to the Japanese economy. The Ainu, most of whom live in Hokkaido, are recognised as the indigenous people of Japan. Many top players of popular spectator sports, including baseball, soccer, and tennis, are the sons and daughters of mixed marriages and these high-profile players hold Japanese passports. The highest-ranking sumo wrestlers, Japan's national sport, have been from Mongolia, Hawaii, and other overseas countries.

These conditions raise the question of who "the Japanese" are [Endo 2019], and what criteria one should use to define "the Japanese" - citizenship, pedigree, language competence, place of residence, or some other dimension? In what sense, for instance, are zainichi Koreans Japanese and why? Are the children of a returnee businessman from overseas assignments more or less Japanese than the Ainu? These questions sensitise the populace to the possible diversity of the Japanese, with their contours obscured and blurred.

Meanwhile, the spread of information technology has enabled its users to observe what is happening not only in their country but also beyond national boundaries, with the consequence that they often realise that they hold analogous values and have similar lifestyles to those abroad. A multitude of virtual communities of urban youth exist across Asia. The same can be said for English-speaking educated people around the world, unifying their 
culture across national borders. Generally speaking, the internet has homogenising functions among the holders of similar class positions in various countries.

With these forces in motion, the shape of Japanese society in the twenty-first century proves to be nebulous, equivocal, and ambiguous, losing previously clear-cut regulatory patterns. This new shape can be called an amorphous society.

\section{Amorphous Dissent: A Reflection of Society at Large}

Political dissent often reflects the elements of the polity that it denounces, while heralding its future configuration. The social movements which erupted in the middle of the 2010 s vividly reflected the amorphous quality of Japanese society at large in its postgrowth phase [Horie - Tanaka - Tanno 2020]. They were initially triggered in 2011 by the meltdown of the nuclear power plant in Fukushima, and again by the introduction of the national security legislation in 2015. Paradoxically, these large-scale movements developed amid the growing fragmentation of social bonds.

As early as 1968, Tsurumi Shunsuke penned a book entitled Futeikei no shisō (Philosophy of amorphousness) [Tsurumi 1968] where he argued that while the everyday thinking of the masses may be neither articulate nor governed by conventional logic, it in fact forms the seeds of productive philosophy in contradicting the well-structured reasoning of the academic elite. He suggested that the very imprecision, ambiguity, and fuzziness of the worldviews of the masses provided the sources of unconventional alternative ideas. His thinking influenced the citizens' movements of the 1960s, especially Koe Naki Koe no Kai (Groups for Voiceless Voices) and Beheiren (The Japan "Peace for Vietnam!" Committee), neither of which had clear leadership structures. These movements were predicated on such principles as "the proposers of new ideas should put them into practice", "do not complain about what other people do", and "do whatever you like to do" [Matsui 2016], visions which were in opposition to the "iron rules" that tended to govern conventional workers" and students' movements at the time.

Similar in style to these citizen' movements, the post-Fukushima protests were indefinite, unstructured, and even amorphous. They can be most starkly contrasted with the so-called Ampo social movements that rose up in 1960 against the ratification of the security treaty between Japan and the United States, arguably the largest mass confrontation on the streets in post-war Japan. The Ampo demonstrations were led by organised student groups and labour unions, which were equipped with regimented internal organisation and solid leadership structures. Student protesters emerged from university student councils, representing their home universities. They banded together through their common university backgrounds as classmates and friends at the same institution. Labour unions also organised themselves, based on each existing union group with tight-knit structures.

Most participants in the post-Fukushima social movements were equipped with different kinds of political capital: Some were the "senior left" who retained their commitments to broadly progressive ideas and organizations since the Ampo years and thereafter. Others were involved in such voluntary associations as NPOs, NGOs and volunteer groups. Most of the protesters on the street were "time rich" and had some organisational footing prior to their participation [Higuchi et al. 2018]. Nonetheless, the post-Fukushima demonstrations differed from the earlier variants, with distinctly loose internal structure and ideology. 
They often changed their leadership from one event to the next. Mobilised by internet communications, many protesters arrived on the street without prior connections with each other. Beyond their key demands concerning nuclear power policies and national security legislation, they called for a wide range of changes with respect to gender equality, sustainable development, and ethnic justice. At times, rallies took on a festive atmosphere, with participants singing, dancing, and using the symbols of popular culture [Brown 2018]. For some, participation itself was of great significance as it empowered them counterculturally. Others found it important to maintain their private spheres of life, even while engaging in collective action. The twenty-first century protests reflected the amorphousness of Japanese society at large, proving to be increasingly unorganised, fluid, and multidimensional, a pattern at variance with the earlier Ampo-type protests.

\section{The Mainstreaming of "Diversity"}

The idea of diversity itself has been diversified. In the Japanese context, it initially sprang up as countercultural vision in opposition to monotonous, establishmentarian, and exclusivist worldviews. The paradigm shift in Japanese studies mentioned at the beginning of the paper resonated with the rise of such forward-looking perspective. Some policy-makers and business leaders, however, have championed the notion of diversity, absorbing the transformative vocabulary into the mainstream in a piecemeal fashion attempts that were conciliatory but often not inclusive of underrepresented groups. In some quarters of Japanese society, diversity without broad inclusiveness has been advanced in adaptation to an emerging amorphous environment.

In the world of gender relations, for example, the Japanese establishment does not hesitate to promote the term, tayōsei (diversity), and encourage companies to appoint women to their boards of directors and other high-ranking posts by head-hunting. The government used diversity as a buzzword in the 2010s, coining the slogan that it will "create a society in which all women shine" [Prime Minister's Office of Japan 2020] and enacting a series of legislation supposed to endorse women's employment. Nonetheless, seven out of ten part-time and casual workers are women. The relative poverty rate of single mothers in Japan exceeds 50 percent [MHLW 2016], the highest among OECD countries. According to the World Economic Forum's Global Gender Gap index, Japan ranked 110th out of 149 countries [World Economic Forum 2018]. The Inter-Parliamentary Union ranked Japan 166th out of 187 nations in terms of the proportion of female parliamentarians in the lower house [Inter-Parliamentary Union 2020]. The reality is that women's status remains very low even in international comparison despite the introduction of the diversity motto, which arguably remains only lip service to gender equality in the twenty-first century.

In an apparently diversified Japan, anti-diversification forces are also at work in many spheres, while the mainstreaming of "diversity" is ostensibly championed at the same time. Husband and wife still have to assume the same surname upon marriage, a civil law requirement that forces nearly all married women to change their surname to their husbands'. Marriage between same-sex couples continues to be illegal. It is also revealing that, while Japan competes with other advanced countries in bringing in skilled workers and professionals from abroad, it accepts a tiny number of refugees, only 42 in 2018, admitting just 0.4 percent of applicants [MOJ 2018], the lowest among advanced economies. In this 
context, the reality behind the use of term "diversity" is not clear-cut. Tokenism, egalitarian symbolism, and public perception massaging often conceal restrictive and exclusive realities.

\section{In Short}

The third opening of Japanese society commenced with two forms of gaiatsu (pressure from outside), one from Euro-American societies regarding trade liberalisation and the other from Asia for the relocation of production sites. These forces eventually led to the deterioration of the industrial sector and the expansion of cultural capitalism in Japan. They also challenged the conventional "Japanese-style" work practices and contributed to the casualisation of labour. Such disintegration attenuated voluntary associations, loosened social bonds between individuals, and gave rise to the diversification of values across social groups. This process coincided with the progress of the information revolution around the world which enabled most people to instantaneously see and appreciate what is happening in other countries, facilitating easy information sharing across national borders. The third turn, thus, made Japanese society more amorphous at multiple levels, while the notion of diversity is accepted variously with intricate nuances and caveats. Even social movements which challenge the existing system tend to be comprised of amorphous qualities, reflecting Japanese society at large. In complex ways, variegated groups are in competition in contemporary Japan over the extent to which diversity is implemented. These conditions that have developed during the last three decades differ sharply from those of the previous decades and mark the beginning of a new configuration of Japanese society.

\section{Bibliography}

Akarui Senkyo Suishin Kyōkai (Association for Promoting Fair Elections) [2020]. Dai 25-kai sangiin giin sōsenkyo zenkoku ishiki chōsa (National survey of consciousness in relation to the 25th House of Councillors elections). Available at: <http://www.akaruisenkyo.or.jp/wp/wp-content /uploads/2011/07/25san_rep.pdf>.

Amino, Yoshihiko [2012]. Rethinking Japanese History. Ann Arbor: University of Michigan Center for Japanese Studies.

Befu, Harumi [2001]. Hegemony of Homogeneity: An Anthropological Analysis of Nihonjinron. Melbourne: Trans Pacific Press.

Brown, Alexander [2018]. Anti-nuclear Protest in Post-Fukushima Tokyo: Power Struggles. London: Routledge.

Chiavacci, David - Homerich, Carola (eds.) [2017]. Social Inequality in Post-growth Japan: Transformation during Economic and Demographic Stagnation. London: Routledge.

Denoon, Donald - Hudson, Mark - McCormack, Gavan - Morris-Suzuki, Tessa (eds.) [1996]. Multicultural Japan: Palaeolithic to Postmodern. Cambridge: Cambridge University Press.

Endo, Masataka [2019]. The State Construction of "Japaneseness": The Koseki Registration System in Japan. Melbourne: Trans Pacific Press.

Fukuoka, Yasunori [2000]. Lives of Young Koreans in Japan. Melbourne: Trans Pacific Press.

Hashimoto, Kenji [2018]. Sengo nōmin-sō no bukai to nōgyō kōzō no tenkan (The class differentiation of peasantry and the conversion of agricultural structure in postwar Japan). In. Takashi Yoshida (ed.). 2015-nen SSM chōsa hōkokusho (Report of the 2015 SSM study), vol. 3, pp. 227-252. 
Higuchi, Naoto [2016]. Japan's Ultra-right. Melbourne: TransPacific Press.

Higuchi, Naoto - Satō, Keiichi - Harada, Shun - Nagayoshi, Kikuko - Matsutani Mitsuru - Ohata, Hiroshi [2018]. 3.11-go no undō sanka: Han-datsu-genpats undō to han-anpo hōsei undō e no sanka o chūshin ni (Social movement participation after 3.11, with a focus on anti- and de-nuclear power movements and anti-security legislation movements). Tokushima Daigaku shakai kagaku kenkyū (Tokushima University social sciences studies) $32: 1-84$.

Horie, Takashi - Tanaka, Hikaru - Tanno, Kiyoto (eds.) [2020]. Amorphous Dissent: Post-Fukushima Social Movements in Contemporary Japan. Tokyo: Trans Pacific Press.

Ishida, Hiroshi - Slater, David (eds.) [2011]. Social Class in Contemporary Japan: Structures, Sorting and Strategies. London: Routledge.

Johnson, Chalmers [1982]. MITI and the Japanese Miracle: The Growth of Industrial Policy 1935-1975. Stanford: Stanford University Press.

Iwabuchi, Koichi - Tsai, Eva - Berry, Chris (eds.) [2020]. Routledge Handbook of East Asian Popular Culture. London: Routledge.

JILPT (Japan Institute for Labour Policy and Training) [2019]. Sengyō shfu to tomo bataraki setai 19802019 (Full-time housewife households and two-income households 1980-2019). Available at: <https:// www.jil.go.jp/kokunai/statistics/timeseries/html/g0212.html>.

Kingston, Jeff [2004]. Japan's Quiet Transformation: Social Change and Civil Society in the 21st Century. London: Routledge.

Kyoto, Shimbun [2020]. Editorial on 31 August. Available at: <https://www.kyoto-np.co.jp /articles/-/349084>.

Lechevalier, Sébastien [2014]. The Great Transformation of Japanese Capitalism. London: Routledge.

Lie, John [2004]. Multiethnic Japan. Cambridge: Harvard University Press.

McGray, Douglas [2002]. Japan's gross national cool. Foreign Policy 44 (11): 44-56.

Matsui, Takashi [2016]. 1960-nendai to "Beheiren" (The 1960s and "The Japan Committee for Peace in Vietnam"). Ōhara shakai mondai kenkyüsho zasshi (Journal of the Ohara Institute for Social Research) 97 (November): 2-15.

MHLW (Ministry of Health, Labour and Welfare) [2016]. Heisei 28-nen kokumin seikatsu kihon chō$s a$ (Basic survey of the life conditions of the Japanese, 2015). Available at: <https://www.mhlw.go.jp /toukei/saikin/hw/k-tyosa/k-tyosa16/dl/03.pdf>.

MHLW (Ministry of Health, Labour and Welfare [2019]. Gaikokujin koyō jōkyō (Employment situations of foreign workers). Available at: <https://www.mhlw.go.jp/stf/newpage_09109.html>.

MHLW (Ministry of Health, Labour and Welfare) [2020]. Jinkō dōtai chōsa (Vital statistics).

MIC (Ministry of Internal Affairs and Communications) [2019]. Rōdō-ryoku chōsa (Labor force survey).

MOJ (Ministry of Justice) [2020]. Reiwa 2-nen ni okeru nanmin ninteisha-sü nado ni tsuite (On the number of persons acceped as refugees in 2020). Available at: <http://www.moj.go.jp/nyuukokukanri/kouhou /nyuukokukanri03_00004.html>.

Mori, Hiroki - Kubo, Yoshiaki [2014]. Dēta kara mita rieki dantain no min’i hyōshutsu: Yūkensha chōsa, rieki dantai chōsa, atsuryoku dantai chōsa (Expressions of popular will through data-based analysis: surveys of voters, interest groups and pressure groups). Nenpō seijigaku (Annals of political science) 65 (1): 200-224.

Mouer, Ross [2015]. Globalizing Japan: Striving to Engage the World. Melbourne: Trans Pacific Press.

Nakakita, Kōji [2017]. Jimin-tō (Liberal Democratic Party). Tokyo: Chūō Kōronsha.

OECD [2019]. Data. Available at: <https://data.oecd.org/gdp/gross-domestic-product-gdp.htm>.

Oguma, Eiji [2014]. The Boundaries of "the Japanese": Korea, Taiwan and the Ainu 1868-1945. Melbourne: Trans Pacific Press.

Pempel, T. J. [1998]. Regime Shift: Comparative Dynamics of the Japanese Political Economy. Ithaca: Cornell University Press.

Pekkanen, Robert J. - Tsujinaka, Yutaka [2014]. Neighborhood Associations and Local Governance in Japan. Routledge: London.

Prime Minister's Office of Japan [2020]. Subete no josei ga kagayaku shakai zukuri honbu (Headquarters to create a society in which all women shine). Available at: $<$ https://www.kantei.go.jp/jp/headline /brilliant_women>. 
SBJ (Statistics Bureau of Japan) [2017]. Census 2015. Available at: <https://www.stat.go.jp/data/kokusei /2015/kekka/kihon3/pdf/gaiyou.pdf>.

SBJ (Statistics Bureau of Japan) [2019]. Tōkei kara mita waga kuni no kōreisha (Statistics of the elderly population in Japan). Available at: https://www.stat.go.jp/data/topics/pdf/topics121.pdf.

Sugimoto, Yoshio [2021]. An Introduction to Japanese Society, 5th edition. Cambridge: Cambridge University Press.

Tachibanaki, Toshiki [2010]. The New Paradox for Japanese women: Greater Choice, Greater Inequality. Tokyo: I-House.

Tsurumi, Shunsuke [1968]. Futekei no shisō (Philosophy of amorphousness). Tokyo: Keisō Shobō.

Vogel, Steven K. [2006]. Japan Remodeled: How Government and Industry Are Reforming Japanese Capitalism. Ithaca: Cornell University Press.

Weiner, Michael (ed.) [2008]. Japan' Minorities: The Illusion of Homogeneity. London: Routledge.

Zielenziger, Michael [2007]. Shutting out the Sun: How Japan Created its own Lost Generation. New York: Vintage Books.

Yoshio Sugimoto is Emeritus Professor of Sociology in the School of Humanities and Social Sciences, La Trobe University, Melbourne. He grew up in Kyoto and graduated from Kyoto University. He obtained a PhD in sociology at the University of Pittsburgh in 1973. He taught and researched at $L a$ Trobe University for more than three decades until his retirement in 2006. He has been a fellow of the Australian Academy of the Humanities since 1988. His latest publication is An Introduction to Japanese Society, fifth edition, Cambridge University Press, 2021. 